\title{
El sistema penal como incentivo a la criminalidad en la contratación pública: aproximación desde el análisis económico del derecho aplicado a mercados implícitos
}

\author{
The Penal System as Incentive to Criminality in Public \\ Procurement: An Approach from the Economic Analysis \\ of the Law Applied to Implicit Markets \\ O sistema penal como incentivo à criminalidade na \\ contratação pública: uma abordagem a partir da análise \\ econômica do direito aplicado aos mercados implícitos
}

\author{
Juan Pablo Sarmiento-Erazo*
}

FECHA DE RECEPCIÓN: 31 DE MARZO DE 2020. FeCha DE APROBACIÓN: 11 DE NOVIEMBRE DE 2020

Doi: https://doi.org/10.12804/revistas.urosario.edu.co/sociojuridicos/a.8858

Para citar este artículo: Sarmiento-Erazo, J. P. El sistema penal como incentivo a la criminalidad en la contratación pública: aproximación desde el análisis económico del derecho aplicado a mercados implícitos. Revista Estudios Socio-Jurídicos, 23(2), 159-185. https://doi.org/10.12804/revistas.urosario.edu.co/sociojuridicos/a.8858

\section{RESUMEN}

En este artículo se argumenta que el sistema penal y penitenciario contiene un conjunto de incentivos y desincentivos que podrían estar estimulando la corrupción en la contratación pública, junto a un conjunto de alternativas jurídicas y materiales que flexibilizan la sanción. Utilizando como estudio de caso el "cartel de la contratación" y aplicando los insumos propuestos por el análisis económico del derecho aplicado a mercados implícitos, se construirá una matriz condicional que podría explicar por qué el mercado de las compras públicas es un lugar común y propicio para la expansión y continuidad de la corrupción y apropiación ilegal de recursos públicos.

Palabras clave: análisis económico del derecho aplicado a mercados implícitos; cartel de contratación; utilidad del delito; costo de cumplimiento; incentivos a la criminalidad en el derecho.

* Abogado de la Pontificia Universidad Javeriana, magíster y doctor en Derecho de la Universidad de los Andes. Profesor de la Universidad del Norte. Correo electrónico: jpsarmiento@ uninorte.edu.co, jua-sarm@uniandes.edu.co. ORCID: https://orcid.org/0000-0002-7303-3300 


\section{ABSTRACT}

This article argues that the penal and penitentiary system contains a set of incentives and disincentives that could be stimulating corruption in public procurement, along with a set of legal and material alternatives that make the sanction more flexible. Using the "contracting cartel" as a case study, and applying the inputs proposed by the economic analysis of the law applied to implicit markets, a conditional matrix will be constructed that could explain why the public procurement market is commonplace and conducive to the expansion and continuity of corruption and illegal appropriation of public resources.

Keywords: Economic analysis of the law applied to implicit markets; utility of the crime; compliance cost; incentives to criminality in the law.

\section{RESUMO}

Este artigo argumenta que o sistema penal e penitenciário contém um conjunto de incentivos e desincentivos que podem estar estimulando a corrupção na contratação pública, juntamente com um conjunto de alternativas jurídicas e materiais que tornam a sanção mais flexível. Utilizando o "cartel da contratação" como estudo de caso, e aplicando os insumos propostos pela análise econômica do direito aplicado aos mercados implícitos, será construída uma matriz condicional que explicará por que o mercado de compras públicas é corriqueiro e propício à expansão e continuidade da corrupção e apropriação ilegal de recursos públicos.

Palavras-chave: análise econômica do direito aplicada aos mercados implícitos; cartel de contratação; utilidade do crime; custo do cumprimento; incentivos à criminalidade no direito. 


\section{Introducción}

El análisis económico del derecho (AED) parte de varios insumos que permiten evaluar la composición normativa y los efectos que podrían llegar a desprenderse de la reforma legal en razón de los incentivos y desincentivos que pueden producirse desde el derecho, como institución que altera las conductas humanas. Uno de los insumos centrales del AED es el REM - reasonable egoist man - (Kazakova, 2014), que supone que el individuo actúa razonablemente y, por esto, se conduce de forma que maximiza su riqueza y, a la vez, la de la sociedad. Un segundo supuesto del AED es considerar el derecho -compuesto por leyes- como "una obligación respaldada por una sanción estatal", en cuyo origen, legisladores y jueces se cuestionan sobre la consecuencia que este tenga en el comportamiento de las personas. Para el AED, las sanciones son precios, razón por la cual los individuos reaccionan a estos de manera idéntica a como responden a los mismos (Kleiman, 2015).

La asimilación de la estructura de costos y utilidades del delito considera también la afectación diferenciada a grupos poblacionales de acuerdo con sus orígenes sociales, niveles educativos, edades, razas, etc. Además, la probabilidad de que un delincuente sea descubierto y condenado y la naturaleza y extensión de los castigos difieren mucho de una persona a otra y de una actividad a otra (Becker, 1968).

Así, el AED aplicado a mercados implícitos supone que el individuo reacciona a la elevación de precios, consumiendo menos del bien más caro, de modo que, si las sanciones generan la misma respuesta que los precios en los individuos, los individuos responden a la sanción más severa, realizando menos esa actividad. En este sentido, el AED presenta una alternativa que cuenta con teorías matemáticas (teoría de precios y juegos) y métodos empíricos razonables (estadística y econometría) para analizar los efectos de los precios sobre el comportamiento (Cooter E Ulen, 1998).

1 Nótese que el AED aborda solo aquellas normas que sancionan, omitiendo aquellas que disponen y enuncian, pues entienden que estas últimas no constituyen una escala de incentivos o desincentivos. 
La aplicación del AED se consideró de especial interés para asuntos como la tributación, la utilidad pública, la regulación de servicios públicos, el derecho a la competencia y la responsabilidad civil (Posner et al., 2011). No obstante, el AED extendido a "mercados implícitos"; es decir, a sanciones jurídicas, ha tenido importantes objeciones que se recogerán brevemente en este documento, principalmente en torno a dos insumos. El primero de ellos, el nivel ilustración y simetría de la información que requiere el REM para tomar una decisión racional; segundo, la batería de fenómenos sociales y morales históricos que pueden definir que una decisión, aunque no maximice utilidades, sea social y moralmente aceptada. Empero, en el mercado de compras públicas, parecería que el nivel de ilustración y la brújula moral determinarían la aplicación de la norma penal, haciendo que esta sea solo una más de las variables de la matriz de costos que asume el contratista o el funcionario público.

En efecto, ¿qué ocurre si la batería de fenómenos sociales y morales incentiva o promueve el rápido enriquecimiento individual y el beneficio particular? ¿Qué ocurre si de la mano de esta brújula moral flexible se eleva el conocimiento sobre las reglas jurídicas, su plasticidad y esto es aplicado por una élite que tiene pleno acceso a la información sobre probabilidad, consecuencias y utilidades esperadas? ¿Qué efectos podría tener la justicia retributiva-premial en la prevención general y especial del delito? Estos interrogantes son los que ilustran este artículo, donde se ha escogido un sistema jurídico complejo como el de la contratación pública y las sanciones penales que se despliegan a partir de ella, para demostrar que si bien el AED aplicado a mercados implícitos ha sido cuestionado, este encuentra un campo fértil para explicar la decisión de quien racionalmente defrauda las reglas de contratación pública y, a la vez, encuentra en el mismo sistema un conjunto de incentivos para cometer conductas contrarias al derecho.

\section{AED aplicado a mercados implícitos}

El AED entiende las leyes y la jurisprudencia como incentivos para el cambio de conductas - precios implícitos- y como instrumentos para el logro de los objetivos de las políticas - la eficacia y la 
distribución- (Cooter E Ulen, 1998). Además, a la vez, comprende al individuo como un maximizador de utilidad -felicidad, satisfacción, beneficios, recaudos, bienestar, deseos, etc.- lo que supone que los sujetos son racionales y, en consecuencia, optimizadores que ordenan alternativas de acuerdo con lo que desean, sujetos a la viabilidad (restricción presupuestaria, por ejemplo).

De esta maximización de utilidades surge, para el AED, el equilibrio entre las interacciones de los actores del mercado (Cooter \& Ulen, 1998). Lo señalado es el resultado del supuesto según el cual los individuos saben lo que quieren y lo que les disgusta y, conjuntamente, tienen la posibilidad de ordenar las diversas combinaciones de bienes y servicios disponibles de acuerdo con su capacidad para satisfacer sus preferencias.

Para explicar mejor al REM, debe entenderse por racional aquel empleo de medios en una cantidad determinada, con la que se maximiza el grado de obtención de los objetivos o se obtiene una proporción de estos con una cantidad mínima de medios. La conducta racional supone entonces metas claramente definidas, instrumentos y el conocimiento de la influencia de esos instrumentos en la meta (Cooter $E$ Ulen, 1998).

En este sentido, el REM persigue sus propios intereses, la mayoría de las veces egoístamente y procede de forma racional para la consecución de ese individualismo metodológico. Es con base en esta suposición que se establecen predicciones sobre los efectos de medidas político-económicas o sobre modificaciones legales y jurisprudenciales en la conducta del sujeto (Schäfer $\mathcal{E}$ Ott, 1991). Dicha racionalidad, además, concierne a la correspondencia entre medios y fines, independientemente de la forma de actuar o los fines o medios que utilice el actor racional (Posner et al., 2011).

Sin embargo, el AED entiende también que las preferencias del consumidor son subjetivas. En otras palabras, distintas personas tienen gustos diferentes, elementos que se dejan para el estudio de la psicología y de la sociología, de forma que los economistas parten de la consideración de que los gustos o las preferencias son "exógenas" y se encuentran establecidas y aparecen como algo dado al individuo (Posner et al., 2011), y aquellas preferencias ajenas a las ya constituidas que se aprecian como externas (Schäfer $\mathcal{E}$ Ott, 1991) en el sentido en que se encuentran fuera del sistema económico. 
En el mismo sentido, el AED reconoce que el comportamiento racional parece ser contrario a lo que se ve comúnmente en la vida económica. Así, por ejemplo, los consumidores con frecuencia compran los productos más caros y otros ni siquiera miran los precios, de modo que, el comportamiento racional no garantiza que se consiga una decisión razonable en cuanto a su resultado (Schäfer E Ott, 1991). Sin embargo, el AED considera que un comportamiento con resultados poco convenientes no rompe la racionalidad de la conducta y reconoce que su aplicación carece de cualidades predictivas absolutas. Empero, en su defensa, se considera que su potencial explicativo se extiende para algunas motivaciones del sujeto, por lo que no puede descartarse su utilidad (Posner et al., 2011).

Así, se entiende como suficiente que las presunciones antepuestas representen una aproximación suficiente a la realidad y coincidan en general con ella, de forma que la hipótesis REM puede ser falsa en un caso individual, pero por ese motivo, considera el AED, no está refutada para el campo de aplicación exigido (Schäfer \& Ott, 1991).

De esta manera, el AED entiende que es posible determinar la conducta o prever el comportamiento del REM respecto de los delitos, entendiendo que las penas, que representan precios a conductas que se pretenden desestimular, traen incentivos implícitos que son eficientes en la medida en que las decisiones que el REM toma, implican una internalización de los costos y beneficios marginales de su acción (Cooter E Ulen, 1998). Así, conseguimos predecir la conducta del sujeto con el objetivo de definir la medida legal o jurisprudencial más eficiente para estimular o no su comportamiento.

Este modelo cuenta con algunas críticas, entre ellas, las que ha realizado North (citado por García et al., 2009), quien rechaza el modelo del actor racional. Para este autor, el cumplimiento de una misma institución o un enunciado normativo puede tener consecuencias diferentes en contextos distintos, debido a que se debe tener en cuenta no solo la norma, sino también la percepción que el individuo tenga de esta en su contexto particular. En este sentido, se genera impredecibilidad en el comportamiento del actor porque su conducta va a encontrarse, en gran medida, influenciada por sus valores, por su percepción de legitimidad 
de la norma o institución que la expide o aplica, que podría elevar los costos morales de la conducta (García et al., 2009).

Las objeciones antes señaladas también son recogidas por Kleiman (2015), para quien, si entendemos que un delincuente es plenamente racional en el sentido económico, debemos asumir que es capaz de elegir entre diferentes acciones la que mejor se adapte a sus preferencias. Algunas de las implicaciones de este modelo simple serán reforzadas si consideramos las características imperfectamente racionales del comportamiento de los seres humanos de carne y hueso; otras deberán ser calificadas. Por ejemplo, el actor racional incumplirá una regla si, y solo si, el beneficio personal (percibido) de irrespetar las reglas supera el costo de hacerlo. La mayoría de los seres humanos reales se comporta de un modo diferente, están bajo la influencia de la conciencia, las costumbres y el hábito, por las ideas sobre lo que es justo y por impulsos que los conducen a actuar de una forma que, de algún modo, ellos "saben" que no es óptima (Kleiman, 2015).

No obstante, pese a las críticas previamente presentadas, el AED concibe el delito doloso como aquel cometido por una persona racional pero amoral, que puede decidir entre cometer o no un delito. Esta persona es entonces aquella que cuidadosamente determina los medios para alcanzar fines ilegales sin ninguna restricción por la culpa o la moral introyectada (Cooter \& Ulen, 1998). Es este supuesto el que permite determinar la pena de una conducta que se quiere desincentivar, para proyectar una norma en la que se contemple una pena más severa de acuerdo con una conducta más grave.

Así, el delincuente, en la búsqueda de su utilidad o de maximizar su riqueza (AED), hará uso del sistema jurídico, incrementando su utilidad hasta el punto en que la utilidad del delito sea mayor al costo de cumplimiento proyectado. Un actor económicamente racional, libre de conciencia o con una "brújula moral flexible" está sujeto a una determinada regla. Si rompe la regla, paga una multa (M). Si la cumple, paga un costo de cumplimiento (C). Por ejemplo, expone Kleiman (2015), una empresa que está sujeta a una reglamentación ambiental puede verse abocada a decidir entre cumplirla e incurrir en mayores costos de producción, o infringirla y pagar una sanción regulatoria. Pero el costo del cumplimiento podría ser un beneficio que se sacrifica, con el propósito 
de obtener lo que el sujeto quiere y que solo se puede lograr rompiendo las reglas. Si el costo del cumplimiento se mantiene constante, ¿qué pasa a medida que la sanción aumenta? Siempre y cuando la multa esté por debajo del costo de cumplir $(M>C)$, el sujeto racional incumplirá la regla y pagará la multa $(\mathrm{M})$. Así que a medida que $\mathrm{M}$ aumenta de $0, C$, la tasa de infracción, permanece constante -el sujeto incumple cada vez- y la sanción total infligida aumenta en concordancia con la sanción por infracción. Si el costo del cumplimiento es de diez dólares, a medida que la sanción pasa de 0 a 9.99 dólares el comportamiento del sujeto sigue igual y, por lo tanto, aumenta el monto de la sanción en realidad impuesta (Kleiman, 2015).

En este marco, cuando el valor de la multa, que está ligeramente por debajo del costo de cumplimiento, aumenta y se ubica ligeramente por encima del costo de cumplimiento: de 9,99 dólares a 10,01 dólares, un sujeto perfectamente racional nunca incumplirá una regla si está seguro de recibir un castigo y si la multa por infringirla es superior a los ahorros o a la ganancia derivada de hacerlo (Kleiman, 2015).

¿Qué ocurre si el monto de la multa permanece fijo, pero la probabilidad varía? Kleiman (2015) explica que una vez más, si la multa es inferior al costo del cumplimiento, la regla será incumplida cada vez. Así que el caso interesante es cuando la sanción de ser sorprendido supera el costo del cumplimiento, pero la probabilidad de ser sorprendido es inferior a la unidad, por ejemplo, el costo del cumplimiento es de 10 dólares y la multa de 20 , entonces el sujeto que toma decisiones racionales, si también es neutro en el riesgo, calculará el valor esperado de la sanción por una determinada infracción, multiplicando los 20 dólares por la probabilidad -Kleiman (2015) la llama P- de recibir castigo si delinque.

En este sentido, para el AED, el REM que comete un delito hace un análisis de probabilidad, donde determinará la posibilidad de ser descubierto, capturado, juzgado y condenado (Cooter \& Ulen, 1998). Entonces, el delincuente despliega un ejercicio racional para calcular la probabilidad del castigo y descuenta la cantidad que espera ganar por la incertidumbre del castigo. Así, el delincuente decide entre la ofensa más favorable al beneficio que espera encontrar; mientras las autoridades que investigan y acusan, según la teoría económica, incrementan el 
esfuerzo por castigar los delitos más graves, de forma que la probabilidad del castigo aumenta con la gravedad del delito (Cooter \& Ulen, 1998).

Por supuesto, podría afirmarse que el AED exige mucho del delincuente, pues debe tratarse de un sujeto informado que conoce los costos, beneficios y probabilidades asociadas con la comisión del delito. El AED explica comportamientos y no procesos subjetivos de razonamiento; es decir, se analiza al sujeto como si estuviese calculando utilidades, pero al mismo tiempo, entiende el AED que el plan criminal debe tener efectivamente la intención de cometer el delito y el delincuente efectúa el razonamiento estadístico y de probabilidad (Cooter \& Ulen, 1998). Con todo, este es probablemente el escenario de las redes de criminalidad que se han construido en torno a la contratación pública y los tipos penales asociados a esta.

Así, el derecho penal se ocupa de razones y no solo de conductas, donde el dolo es entonces una forma de razonamiento que permite analizar económica y descriptivamente la conducta del delincuente. En el marco de lo anterior, el propósito del AED en intentar convertirse en instrumento para tener en cuenta al momento de crear una norma, en especial una penal, se consolida al entender que la sanción penal óptima es aquella que persuade al criminal (reduce la utilidad del delito), cuando este encuentra que la sanción empeora su situación si comete el delito (Posner, 1998). Esto quiere decir que quien comete un delito, lo hace porque ha encontrado que su utilidad proyectada supera el costo de cumplimiento. La severidad óptima depende de la gravedad de la conducta que pretende desincentivar el legislador al definir la pena del delito, determinable en costos sociales; es decir, el costo que representa a la sociedad la comisión de un determinado delito y para el Estado castigarlo.

Entonces, en la medida en que una sanción penal consiga la disuasión, el Estado reduce la demanda de delitos fijando un precio por la conducta punible bajo la forma de un costo esperado de tener que pagar una multa o ir a prisión por realizar ese comportamiento, pero, desde este punto de vista económico, los sujetos solo son enviados a la cárcel para mantener la credibilidad del instrumento de disuasión (Posner, 1998). En otras palabras, se hace uso de la teoría microeconómica de la demanda, donde el precio (pena) determina el nivel de consumo de 
un determinado bien o servicio, en este caso, la pena como significante de algún costo y siempre que exista la efectiva punición por parte del aparato estatal con el objetivo de lograr la certera persuasión del delincuente. En este sentido, el AED entendería que el delincuente accede a una utilidad marginal en el momento en que consume una unidad más del bien (delito) que, pese a la intención del legislador, genera un estímulo o incentivo al delincuente intencional. El resultado al que se llega es el más eficiente, pues los costos son inferiores a la utilidad en una importante medida.

La justificación del AED aplicado a mercados implícitos, así como los insumos que devienen de él, permitirá abordar el objeto de observación, cruzando las variables normativas de la contratación pública, el derecho penal y las reglas penitenciarias. A continuación, se tratarán entonces los aspectos normativos que permiten construir la matriz condicional e ilustran cómo la conjugación de estas variables jurídicas ofrece un abanico de incentivos a la criminalidad, considerando los costos y volumen de recursos, así como la asimetría de información, que facilitan la cooptación del contrato administrativo y la función pública.

\section{Los incentivos a la criminalidad en las reglas de contratación pública y las alternativas penales y penitenciarias}

Luego del contexto aportado por el AED aplicado a mercados implícitos, entraremos a revisar las alternativas penales y penitenciarias que permiten nutrir la matriz condicional de incentivos y desincentivos, así como los efectos de la justicia premial o el sistema de delación compensada (González, 2007). Kleiman (2015) expone que el simple hecho de aumentar la capacidad sancionatoria, incluso de modo temporal, puede impulsar el sistema hacia un estado de baja contravención que entonces puede mantenerse con una capacidad sancionatoria menor que la requerida para lograrlo en primer lugar. Sin embargo, para que eso funcione, explica el mismo autor, la capacidad debe superar un valor crítico, en donde este dependerá de la distribución inicial de las propensiones a contravenir, de qué tanto una contravención no castigada 
aumente la tasa de contravenciones futuras y de cuánto una contravención castigada la disminuya. Si no se agrega suficiente capacidad instrumental del Estado, el aumento de la sanción es "peor que inútil: multiplica las sanciones sin reducir mayor cosa las contravenciones" (Kleiman, 2015, p. 61).

Esta precisión supone entonces balancear el costo de cumplimiento (C), la utilidad del delito (M) y la capacidad instrumental del Estado para hacer efectiva la sanción (P). A lo señalado, resulta importante agregar una moralidad convencional -que determina los costos morales - construida a partir de lo que hemos llamado una brújula moral flexible $\left(C_{-1}\right)$, que finalmente neutralizaría otros valores sociales o morales que se encuentran en juego (García et al., 2009).

En la medida en que "intuiciones morales diarias" (Posner, 1998b) se han construido en el marco de una "brújula moral flexible", esta puede facilitar una decisión "monstruosa", pero altamente rentable. En efecto, defraudar un contrato administrativo destinado para la alimentación o atención de salud de niños enfermos y apropiarse de esos recursos públicos puede explicarse desde un análisis frívolo, pero más aproximado al funcionario o contratista que tiene a su disposición la aplicación o inaplicación de las reglas de la contratación pública, cuyo interés es el incremento patrimonial. Así, en la medida en que las convenciones morales no aportan elementos suficientes para censurar una conducta "moralmente monstruosa", como la descrita, pues la maximización de la riqueza es justamente el fin que persiguen los individuos $\left(\mathrm{C}_{-1}\right)$, el análisis de utilidades encuentra una neutralización o inclusive un incentivo a la criminalidad. Kleiman (2015) ofrece el siguiente ejemplo, a manera ilustrativa:

En el caso del robo a propiedades, gracias a los informes de las víctimas, tenemos una idea aproximada del "botín". En 1974, la víctima de robo domiciliario reportaba en promedio haber perdido unos cuatrocientos dólares (aproximadamente equivalente a 1600 dólares actuales); pero en promedio la ganancia para el ladrón (o los ladrones) habría sido mucho menor. Parte de la pérdida reportada reflejaba el daño causado en el transcurso del robo más que la propiedad retirada por el ladrón, más aún los elementos robados, exceptuando el efectivo 
y las armas, le generan al ladrón, cuando los venda a un traficante de artículos robados o a un conocido, quien pagará mucho menos del valor que pagó el comprador inicial. Si le asignamos al ladrón una ganancia promedio igual al 20\% de la pérdida incurrida por la víctima, los cuatrocientos dólares que en promedio perdieron los propietarios se traducirían en la ganancia promedio para el ladrón de apenas ochenta dólares aproximadamente (unos 320 dólares actuales). Si se divide eso por el castigo promedio de cuatro días, nos resulta un salario promedio por robo; por días pasados tras las rejas, de unos veinte dólares en dinero de 1974, o unos ochenta en moneda actual. En el 2007, el auge de la construcción de prisiones y el colapso del crimen de finales de los años noventa se tradujeron en una cantidad de días por robo hasta de dieciséis días, mientras que, haciendo los ajustes por inflación, el "botín" del robo había aumentado muy ligeramente. Por lo tanto, el "salario" del ladrón había disminuido en un 75\% y era de unos veintidós dólares por día de reclusión. Cuando los parámetros se expresan con tal claridad, el robo a propiedades no aparece como una propuesta atractiva. Parece improbable que muchos de los ladrones de propiedades aceptaran la oferta directa de pasar un día en la cárcel a cambio de veintidós dólares, o dieciséis días por 350 dólares, incluso si el dinero se les pagara de entrada, e incluso haciendo caso omiso de otros costos y riesgos relacionados con entrar a las casas -por ejemplo, que el propietario lo hiriera de un disparo (p. 84).

Este autor, inclusive, se aproxima al objeto del presente documento al señalar que

tal vez el problema es que para muchos muchachos de los vecindarios donde se cría la mayoría de los ladrones, el robo a propiedades (o el menudeo de drogas) es una actividad honorable y una cuestión de hombría (...mientras que los empleos] legítimos disponibles para los que no gozan de mayores destrezas vendibles se consideran degradantes o humillantes (p. 86).

Si eso es así, continua Kleiman (2015), entonces la estrategia clave, para hacer que el crimen no pague a los ojos de quienes lo cometen, estribaría en cambiar sus percepciones sobre el delito, por una parte, y sobre hacer trabajos considerados de baja categoría, por otra. Con todo, 
concluye Kleiman (2015), agregar más celdas a las cárceles difícilmente aporta a alguno de esos proyectos.

Ahora bien, para la hipótesis que nos ocupa, la matriz puede ser aparentemente más compleja y, más importante, no estamos hablando de ladrones de casas o microtraficantes de drogas. Estamos frente a élites bien informadas con acceso a servicios jurídicos de gran capacidad y acceso a redes de poder, que, al final, cuentan con medios financieros para determinar si el sistema legal de la contratación pública se aplica o no. Así, la matriz podría condensarse de la siguiente manera:

\begin{tabular}{|c|c|c|c|}
\hline $\begin{array}{l}\text { Utilidad del delito } \\
\text { (M) }\end{array}$ & Costos (sanción) & Beneficios procesales & $\begin{array}{c}\text { Beneficios } \\
\text { penitenciarios }\end{array}$ \\
\hline $\begin{array}{l}\text { Valor del contrato } \\
\text { público } \\
M\end{array}$ & $\begin{array}{l}\text { Meses de reclusión } \\
\text { C }\end{array}$ & $\begin{array}{l}\text { Principio de } \\
\text { oportunidad } \\
D\end{array}$ & $\begin{array}{l}\text { Redención de pena } \\
\text { por trabajo, estudio o } \\
\text { enseñanza } \\
D_{1}\end{array}$ \\
\hline \multicolumn{4}{|c|}{ Costos de servicios jurídicos especializados $C_{t}$} \\
\hline $\begin{array}{l}\text { Acceso a redes de } \\
\text { criminalidad que } \\
\text { permanecen luego } \\
\text { de la sanción } \\
M_{1}\end{array}$ & $\begin{array}{l}\text { Acceso a redes de } \\
\text { criminalidad que se } \\
\text { encuentran privadas } \\
\text { de la libertad } \\
\mathrm{M}_{2}\end{array}$ & $\begin{array}{l}\text { Sentencia anticipada } \\
D_{2}\end{array}$ & $\begin{array}{l}\text { Prisión domiciliaria } \\
D_{3} \\
\text { Condiciones } \\
\text { especiales de reclusión } \\
D_{4}\end{array}$ \\
\hline
\end{tabular}

Fuente: elaborado a partir de disposiciones contenidas en el Código Penal y la Ley 65 de 1993.

La anterior matriz se podría enriquecer con un análisis del sistema de delación compensada, donde los actores racionales pueden optar por delatar a sus cómplices, con el propósito de obtener una sanción más beneficiosa (Uribe, 2018). En el caso colombiano se materializa quizá con el principio de oportunidad, donde el funcionario o contratista acusado, opta por denunciar a sus cómplices en la captura ilegal del contrato estatal y obtiene con ello un trato penal más favorable.

Ahora bien, siguiendo con el ejemplo propuesto por Kleiman (2015), pensemos por un momento en el abanico de alternativas que tiene el contratista o funcionario público que defrauda el proceso de contratación pública y, a la vez, los incentivos que supone el sistema penal. En 2018, 
un contratista decide sobornar a un funcionario público ${ }^{2}$ para que este publique unos pliegos de condiciones a la medida de las capacidades financieras, jurídicas y operativas del proponente -y futuro contratista-, y promete dividir las utilidades de dicho contrato, entregándole al funcionario un porcentaje del contrato. Una vez adjudicado el contrato, el contratista vincula al interventor a la red de criminalidad, quien certifica avances y calidades de obra que no corresponden a la realidad. Esto supondría, como se expondrá más adelante, que el "soborno compensatorio" permitiría al contratista y al interventor, aprovechar la asimetría de información que impiden detectar informes erróneos (Fearon $\varepsilon$ Busch, 2006). Adicionalmente, la participación accionaria horizontal o

2 En el sistema penal se evidencia una asimetría en la punición entre el servidor público y el contratista. Para el primero, existen tres delitos especiales, destinados a castigar la celebración indebida de contratos, mientras que al contratista solo le atañe uno de ellos (artículo 410-A). A saber: Artículo 408 del Código Penal. Violación del Régimen Legal o Constitucional de Inhabilidades e Incompatibilidades: El servidor público que en ejercicio de sus funciones intervenga en la tramitación, aprobación o celebración de un contrato con violación al régimen legal o a lo dispuesto en normas constitucionales, sobre inhabilidades o incompatibilidades; artículo 409 del Código Penal. Interés indebido en la celebración de contratos: El servidor público que se interese en provecho propio o de un tercero, en cualquier clase de contrato u operación en que deba intervenir por razón de su cargo o de sus funciones; artículo 410 del Código Penal. Contrato sin cumplimiento de requisitos legales: El servidor público que por razón del ejercicio de sus funciones tramite contrato sin observancia de los requisitos legales esenciales o lo celebre o liquide sin verificar el cumplimiento de los mismos; artículo 410-A. Acuerdos restrictivos de la competencia (artículo 27 de la Ley 1474/11). El que en un proceso de licitación pública, subasta pública, selección abreviada o concurso se concertare con otro con el fin de alterar ilícitamente el procedimiento contractual. Por otra parte, estos delitos pueden concursar con otros como: artículo 405 del Código Penal. Cohecho propio. Modificado por el art. 33, Ley 1474 de 2011. El servidor público que reciba para sí o para otro, dinero u otra utilidad, o acepte promesa remuneratoria, directa o indirectamente, para retardar u omitir un acto propio de su cargo, o para ejecutar uno contrario a sus deberes oficiales; artículo 406 del Código Penal. Cohecho impropio. Modificado por el artículo 33, Ley 1474 de 2011. El servidor público que acepte para sí o para otro, dinero u otra utilidad o promesa remuneratoria, directa o indirecta, por acto que deba ejecutar en el desempeño de sus funciones [...] El servidor público que reciba dinero $u$ otra utilidad de persona que tenga interés en asunto sometido a su conocimiento; artículo 407 del Código Penal. Cohecho por dar u ofrecer. El que dé u ofrezca dinero u otra utilidad a servidor público, en los casos previstos en los dos artículos anteriores; artículo 397 del Código Penal. Peculado por apropiación. Modificado por el artículo 33, Ley 1474 de 2011. El servidor público que se apropie en provecho suyo o de un tercero de bienes del Estado o de empresas o instituciones en que éste tenga parte o de bienes o fondos parafiscales, o de bienes de particulares cuya administración, tenencia o custodia se le haya confiado por razón o con ocasión de sus funciones; artículo 400 del Código Penal. Peculado culposo. El servidor público que respecto a bienes del Estado o de empresas o instituciones en que éste tenga parte, o bienes de particulares cuya administración, tenencia o custodia se le haya confiado por razón o con ocasión de sus funciones, por culpa dé lugar a que se extravíen, pierdan o dañen. 
cruzada (San Miguel-Giralt, 2017), que también se expondrá con más detalle a continuación, inhibiría las sanciones administrativas que puede imponer la administración al contratista incumplido.

En efecto, en materia contractual, se han dispuesto varias exorbitancias que permiten sancionar al contratista incumplido: la caducidad, la multa y el incumplimiento. La caducidad es una sanción resolutoria, que implica la inhabilitación por 5 años del contratista, de acuerdo con lo dispuesto en el artículo 8 de la Ley 80 . Esa inhabilidad inclusive se transmite a las sociedades en las que los contratistas sancionados tengan participación. La multa puede ser pactada por las partes como potestad excepcional e imponerse unilateralmente, pues según se vio, dicha facultad deviene directamente de la ley y no del pacto o convención contractual. La multa se deriva de la facultad de la administración para tomar las medidas de control e intervención necesarias, que garanticen la ejecución del objeto contratado (Caducidad, artículo 18 párr. 2). ${ }^{3}$ Con todo, tanto la Ley 1474 de 2011, como el artículo 183 de la Ley 1801 del 29 de julio 2016 pueden inhabilitar al contratista por la acumulación de multas o la mora en el pago de estas. Quizá, al tratarse de una sanción que busca constreñir, coaccionar, compulsar o apremiar el cumplimiento del objeto contractual, no hay una incidencia relevante de este desincentivo al incumplimiento contractual en la matriz condicional. Igualmente, la citada Ley 1474 establece el incumplimiento como una potestad contractual que puede conducir, al igual que la acumulación de multas, a configurar el incumplimiento reiterado y, con ello, provocar la inhabilitación del contratista.

No obstante, como se expone en este documento, la participación accionaria horizontal o cruzada, además de ocultar una práctica anticompetitiva y colusoria en algunos casos, también permite inhibir los efectos de las sanciones administrativas antes citadas. Es probable, como se indicará en la matriz condicional propuesta, que estas sanciones

3 La jurisprudencia ha discutido constantemente sobre la naturaleza de la multa. Sobre la naturaleza convencional y exorbitante, ver Consejo de Estado, Sección Tercera Subsección B Consejero ponente: Ramiro Pazos Guerrero Sentencia del 3 de agosto de 2017, Radicación número: 15001-23-31-000-1996-16048-01 (37934). Ver también Cámara de Comercio de Bogotá, Centro de Arbitraje y Conciliación, Tribunal de Arbitraje de Sociedad Concesionaria Operadora Aeroportuaria Internacional-OPAIN S. A. contra Agencia Nacional de Infraestructura, Laudo del 27 de febrero de 2019. 
produzcan e incentiven la captura del interventor-supervisor del proyecto, en la medida en que, en cualquier caso, sería indeseable la imposición de la sanción. Con todo, la capacidad de negociación del contratista y estas alternativas accionarias, como se indicó, permite eludir los efectos de la sanción administrativa.

Supongamos que, en el proceso de ejecución del contrato, el aparato judicial se activa. Esto conduciría a que el contratista cuente con dos alternativas: comparte las utilidades con el investigador o juzgador, o el órgano judicial cuenta con una persona honesta, con una "brújula moral estricta", que impide que se pueda transar el proceso judicial. En el primer escenario, simplemente asignaría en su estructura de gastos, un costo asociado a evitar el precio final (sanción), pero conserva las utilidades derivadas de la comisión del delito. En el segundo escenario, debe contar con servicios jurídicos especializados que logren, en un primer caso, exonerar de responsabilidad al funcionario y al contratista, sea por una defensa sustantiva o por su participación en otras redes de criminalidad o de poder que exoneren o flexibilicen la decisión, o un segundo caso, que se obtengan cuatro beneficios, que no son excluyentes: la prisión domiciliaria, la sentencia anticipada, el principio de oportunidad y las condiciones especiales de reclusión y redención de la pena por estudio, educación o trabajo.

Claro, al anterior escenario podrían agregarse otras utilidades que se pueden construir a la luz de la contratación pública. Por ejemplo, iniciar un proceso judicial por el rompimiento del equilibrio económico del contrato; acordar con los demás proponentes que se vieron defraudados en el trámite de selección del contratista, el inicio de procesos de nulidad y restablecimiento del derecho, que les reconozca la utilidad esperada por cuenta del contrato que no se les adjudicó; la convocatoria a un tribunal de arbitramento para el ajuste del precio licitado, etc.

En la figura 1, debemos considerar que la activación del aparato judicial, así como los resultados del proceso judicial son inciertos. La mora judicial se convierte en un incentivo en el sistema, pues consigue que, en muchas ocasiones, los términos para adelantar la investigación, definir la situación jurídica y juzgar a la persona investigada se venzan y así, se obtenga una resolución favorable sin una decisión de fondo. 
Figura 1. Matriz condicional de la red de criminalidad

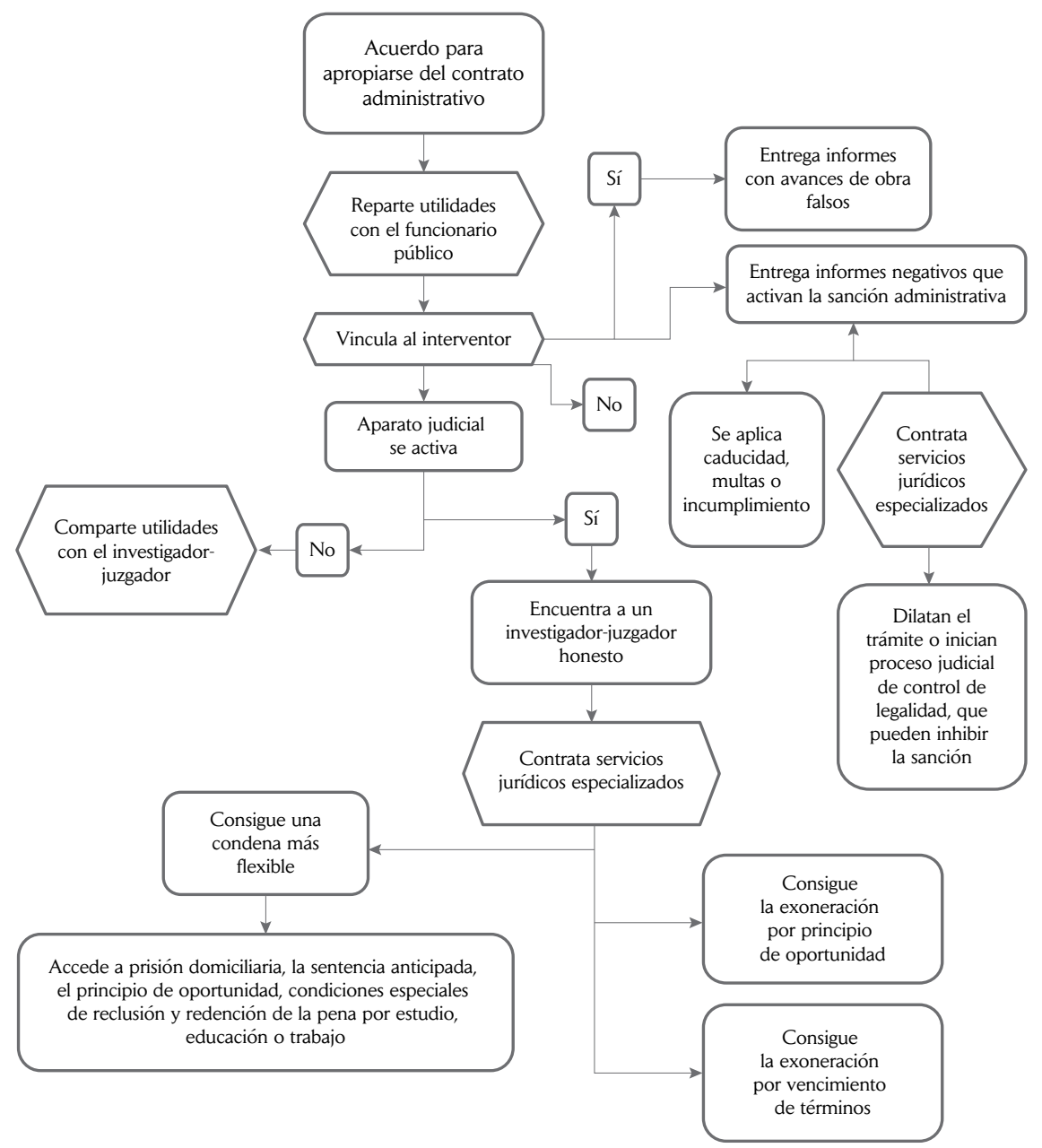

Con todo, no existen datos oficiales sobre estas redes activas de criminalidad en esta materia, pero lo anterior permite identificar un primer reflejo de los incentivos jurídicos y extrajurídicos que limitan severamente la eficacia de las reglas de contratación pública y las sanciones sobre su incumplimiento.

Ahora bien, un dato que se puede extraer con mayor precisión es el "peor escenario" del cálculo de costos (sanciones) que se pueden producir a la luz del fraude al contrato público. Como se mencionó previamente, los meses de reclusión mencionados dependerán de los delitos que sean imputados y efectivamente sancionados mediante sentencia. 
Tabla 1. Delitos relacionados con la contratación pública

\begin{tabular}{|l|l|}
\hline \multicolumn{1}{|c|}{ Delito } & \multicolumn{1}{c|}{ Pena } \\
\hline Peculado por apropiación & $\begin{array}{l}\text { Seis (6) a quince (15) años, multa equivalente al valor de } \\
\text { lo apropiado sin que supere el equivalente a cincuenta } \\
\text { mil (50000) salarios mínimos legales mensuales } \\
\text { vigentes, e inhabilitación para el ejercicio de derechos } \\
\text { y funciones públicas por el mismo término. Si lo } \\
\text { apropiado supera un valor de doscientos (200) salarios } \\
\text { mínimos legales mensuales vigentes, dicha pena se } \\
\text { aumentará hasta en la mitad }\end{array}$ \\
\hline Cohecho propio & $\begin{array}{l}\text { Cinco (5) a ocho (8) años, multa de cincuenta (50) a } \\
\text { cien (100) salarios mínimos legales mensuales vigentes }\end{array}$ \\
\hline Cohecho impropio & $\begin{array}{l}\text { Cuatro (4) a siete (7) años, multa de cincuenta (50) a } \\
\text { cien (100) salarios mínimos legales mensuales vigentes }\end{array}$ \\
\hline Cohecho por dar u ofrecer & $\begin{array}{l}\text { Tres (3) a seis (6) años, multa de cincuenta (50) a cien } \\
\text { (100) salarios mínimos legales mensuales vigentes }\end{array}$ \\
\hline $\begin{array}{l}\text { Violación del régimen legal o } \\
\text { constitucional de inhabilidades } \\
\text { e incompatibilidades }\end{array}$ & $\begin{array}{l}\text { Cuatro (4) a doce (12) años, multa de cincuenta (50) } \\
\text { a doscientos (200) salarios mínimos legales mensuales } \\
\text { vigentes }\end{array}$ \\
\hline $\begin{array}{l}\text { Interés indebido en la } \\
\text { celebración de contratos }\end{array}$ & $\begin{array}{l}\text { Cuatro (4) a doce (12) años, multa de cincuenta (50) } \\
\text { a doscientos (200) salarios mínimos legales mensuales } \\
\text { vigentes }\end{array}$ \\
\hline $\begin{array}{l}\text { Contrato sin cumplimiento de } \\
\text { requisitos }\end{array}$ & $\begin{array}{l}\text { Cuatro (4) a doce (12) años, multa de cincuenta (50) } \\
\text { a doscientos (200) salarios mínimos legales mensuales } \\
\text { vigentes }\end{array}$ \\
\hline $\begin{array}{l}\text { Seis (6) a doce (12) años y multa de doscientos (200) a } \\
\text { mil (1000) salarios mínimos legales mensuales vigentes }\end{array}$ \\
\hline competencia
\end{tabular}

De la tabla 1, podemos constatar la pluralidad de conductas típicas que pueden imputarse, directamente relacionadas con el manejo del contrato administrativo. Sin embargo, en el régimen de contratación, el contratista solo puede cometer los delitos de acuerdos restrictivos de la competencia y cohecho por dar u ofrecer. Sin embargo, el funcionario público se expone a mayores consecuencias jurídicas y, por ello, su utilidad del delito debe ser mucho mayor. De allí que los funcionarios públicos responsables de la contratación pública encuentren un incentivo en la integración de redes de criminalidad que provoca el mismo sistema, al generar esta asimetría punitiva.

Quizá por ello, la práctica anticompetitiva más común sea la colusión vertical, es decir, con la participación de las propias autoridades 
involucradas en la convocatoria (San Miguel-Giralt, 2017). Esta colusión se facilita, además, si consideramos la escases de competidores, lo cual reduce la concurrencia, facilita la concentración del mercado de compras públicas y perpetúa a escasas empresas con grandes márgenes de utilidad (San Miguel-Giralt, 2017).

Aunque la auditoría o interventoría del contrato podría constituir un espacio o ámbito de vigilancia y control, como se indicó en la matriz condicional, puede ser relativamente fácil cooptar la función de vigilancia, agregando más costos al punto de equilibrio del contrato. En efecto, puede existir un "equilibrio de soborno" cuando la entidad sea corruptible y la capacidad de negociación del corruptor sea suficiente, dado el poder de negociación de la empresa (Fearon, 2009). Así, el "soborno compensatorio", junto con la asimetría de información que implica recursos y capacidades institucionales muchas veces imposibles de compensar impiden detectar informes erróneos después de recibir señales de sobre costos (Fearon $\mathcal{E}$ Busch, 2006). Esto último explicaría por qué, en la matriz condicional propuesta, el interventor puede integrarse con relativa facilidad a la red de criminalidad que explica la apropiación y cartelización de la contratación estatal.

Lo expuesto no puede dejar de lado la "justicia retributiva-premial", que permite la redención de la pena por estudios, trabajo o educación. Aquí ya no juega solo el derecho penal, sino el régimen penitenciario (Ley 65 de 1993).

Tabla 2. Justicia premial y redención de la pena

\begin{tabular}{|l|l|}
\hline \multicolumn{1}{|c|}{ Requisitos para la redención } & \multicolumn{1}{c|}{ Tiempo de redención de la pena } \\
\hline Educación & Un día de reclusión por dos días de estudio \\
\hline Instrucción o enseñanza & $\begin{array}{l}\text { Cuatro horas de enseñanza se le computan } \\
\text { como un día de estudio }\end{array}$ \\
\hline $\begin{array}{l}\text { Actividades literarias, deportivas, artísticas } \\
\text { un día de reclusión por dos días de estudio }\end{array}$ & $\begin{array}{l}\text { Un día de reclusión por dos días de estas } \\
\text { actividades }\end{array}$ \\
\hline Trabajo & Un día de reclusión por dos días de trabajo \\
\hline
\end{tabular}

La tabla 2 ilustra los beneficios penitenciarios, que se pueden acumular con los procesales, y que se integran a la matriz de incentivos que pueden existir para la criminalidad. Esta tabla ha excluido beneficios 
procesales como la sentencia anticipada, consagrada en el Código de Procedimiento Penal del 2000, que consiste en una solicitud del procesado, quien se acoge a las pruebas practicadas por la Fiscalía y suscribe un acta donde se consignan los hechos que se han aceptado. Esta acta y las diligencias adelantadas por la Fiscalía se remiten al juez competente, quien dicta sentencia de acuerdo con los hechos y circunstancias aceptadas. Si la sentencia anticipada se realiza en la primera etapa del proceso (indagación), la pena se disminuirá en una tercera parte. Si la solicitud de sentencia anticipada y aceptación de los cargos ocurre luego de proferida la resolución de acusación y antes de que quede ejecutoriada la providencia que fija la fecha para la celebración de la audiencia pública, la rebaja de la pena será de una octava parte de la pena. Cuando las rebajas por confesión y sentencia anticipada concurren en la etapa de instrucción, la rebaja será de las dos quintas partes y cuando concurren en la etapa de juzgamiento, será de una quinta parte. El Código de Procedimiento Penal vigente (Ley 906 de 2004) regula los preacuerdos entre la Fiscalía y el acusado y permiten que, entre otros, se elimine de su acusación alguna causal de agravación punitiva o algún cargo específico o se tipifique la conducta, dentro de la alegación conclusiva de la Fiscalía, de una forma específica con miras a disminuir la pena. Igualmente, si la aceptación de los cargos se produce en la audiencia de formulación de la imputación, el procesado puede acceder a la rebaja hasta de la mitad de la pena. Si la aceptación se produce en audiencia preparatoria, la pena se puede reducir hasta en la tercera parte y si la misma se produce en el juicio oral, se reducirá hasta en una sexta parte.

A lo señalado habrá que agregarle los beneficios por colaboración, que permiten que el funcionario o contratista que ha cometido alguno o varios de los delitos enunciados previamente pueda reducir la pena de una sexta hasta una cuarta parte de la pena, sustituir la cárcel por prisión domiciliaria, acceder a la suspensión condicional de la ejecución de la pena o, inclusive, la libertad condicional.

El Código de Procedimiento Penal de 2004 fortaleció la "justicia retributiva-premial", entendida como el incentivo a la conducta realizada ante el procesamiento y el castigo, más que al delito cometido; así, los mayores beneficios se otorgarán a quienes más colaboren en el proceso 
- confesando o delatando- y a la conducta en el establecimiento de reclusión (Restrepo, 2015). En efecto, el Código de 2004 establece también el principio de oportunidad, que le permite a la Fiscalía General de la Nación suspender, interrumpir o renunciar a la persecución penal. Entre las causales pertinentes para el objeto de estudio, se encuentran la colaboración eficaz para evitar que continúe el delito o se realicen otros, aportar información esencial para la desarticulación de bandas de delincuencia organizada -redes de criminalidad- o cuando el imputado sirva como testigo principal contra los demás intervinientes.

Nos queda por agregar otro factor que neutraliza con mayor profundidad los efectos de las sanciones impuestas por la autoridad competente. La participación accionaria horizontal, que consiste en que un competidor del mercado cuenta, en su estructura accionaria, con un número determinado y muy reducido de inversionistas comunes con una cuota de participación sustancial (San Miguel-Giralt, 2017). Esta participación accionaria, también llamada participación cruzada, tiene límites establecidos en los artículos 8 y 9 de la Ley 80 de 1993, reformada continuamente para ampliar el Régimen de Inhabilidades e Incompatibilidades, que en cualquier caso puede eludirse, pues las operaciones accionarias y de valores, así como la intermediación de terceros (agentes sustitutos) ocultan con relativa facilidad la participación reiterada de contratistas sancionados en el mercado de las compras públicas. Así, en un mercado concentrado o con pocos competidores, la exclusión de uno de ellos por sanciones administrativas, disciplinarias, fiscales o penales encuentra formas organizadas, algunas complejas, otras no tanto, de contar con una participación accionaria cruzada que les permite eludir las consecuencias de dichas sanciones.

Inclusive, tanto la participación accionaria cruzada, como los acuerdos colusorios horizontales (entre proponentes) pueden conducir a posturas encubiertas - cover bidding-, oferta de resguardo, oferta complementaria $\mathrm{u}$ oferta simbólica, sea por medio de postores reales o fantasma. Estos acuerdos simulan una competencia o realizan ofertas destinadas a fracasar, con el propósito de fingir una concurrencia amplia cuando, en realidad, están orientadas a apartar a otros competidores o, simplemente, simular un espacio amplio de competencia. Las formas de posturas encubiertas son variadas, como la supresión de ofertas, la rotación de 
ofertas o la asignación de mercados (San Miguel-Giralt, 2017), pero al final, consiguen la apropiación del mercado de compras públicas y la adjudicación del contrato.

Ahora bien, sin el ánimo de ser exhaustivo o convertir este trabajo en un manual para el cálculo de costos de cumplimiento (C), utilidades del delito $(\mathrm{M})$ o probabilidad de la sanción $(\mathrm{P})$, podríamos decir que una persona que haya cometido algunos de los delitos asociados a la contratación pública podría extinguir la pena por aplicación del principio de oportunidad o reducir significativamente la punición de la misma o, en cualquier caso, purgar la pena y acceder sea por trabajo, enseñanza e instrucción o educación a una redención parcial de la pena.

Para ilustrar las variables antes enunciadas, podemos tomar como ejemplo algunos casos que han sido resueltos recientemente. El exalcalde, Samuel Moreno, de Bogotá fue hallado culpable por los delitos de cohecho propio e interés indebido en la celebración de contratos y se le impuso la pena principal de 298 meses de prisión y una multa de 361 salarios mínimos legales mensuales vigentes. Esto es, 24 años de prisión. En este escenario, el funcionario asumió los costos de un proceso judicial y realizó una apuesta de vencer a la Fiscalía en el proceso. Sin embargo, podemos hacer un análisis hipotético considerando la cantidad de años que ha sido condenado.

Supongamos que el sistema judicial se activa, como ocurrió en el caso enunciado, y el funcionario llega a un preacuerdo con la Fiscalía. En ese caso, hubiese eliminado los agravantes que se le imputaron y su pena hubiese sido inferior, pero el proceso hubiera continuado, en la medida en que el preacuerdo tiene efectos limitados, como se enunció previamente. Con todo, supongamos que el imputado hubiera aceptado los cargos en audiencia de formulación de la imputación, en ese caso, la rebaja hubiera sido de hasta la mitad de la pena (hubiera pasado de 219 meses a 108 meses, aproximadamente). Ahora bien, si la aceptación se hubiera producido en audiencia preparatoria, la pena se habría reducido hasta en la tercera parte la pena (pasaría de 219 meses a 146, aproximadamente) y si esta aceptación se hubiera realizado en el juicio oral, la pena se habría reducido hasta una sexta parte de la pena (habría sido de 182 meses). Lo anterior, sin descartar otras alternativas que se enunciaron, como acogerse al principio de oportunidad 
o colaborar eficazmente para desmantelar la red de criminalidad en torno a la contratación pública y, en ese caso, hubiera logrado que la fiscalía suspendiera la persecución penal.

En las tres alternativas antes enunciadas, podemos continuar con la reducción de penas. Así, si el inculpado no lograse que se le concediera prisión domiciliaria, podría trabajar, estudiar o impartir clases, consiguiendo una reducción significativa de la pena. Esto quiere decir que, si la sentencia era de 108 meses, la realización de las mencionadas actividades podría reducir la privación de la libertad a 54 meses o de 146 se reduciría a 73, y los 182 meses pasaría a 91 meses. Ahora bien, según el proceso judicial, el exalcalde de Bogotá recibió 1.5 millones de dólares por la celebración de este contrato. Obviamente, se trata de recursos que no se han rastreado, en la medida en que operaciones financieras transnacionales pueden facilitar el ocultamiento de estos recursos, pero los testimonios recaudados en el proceso judicial dan cuenta del valor señalado. Inclusive, como se anticipó, la participación accionaria horizontal podría eludir las consecuencias jurídicas de la sanción administrativa y penal contra el grupo empresarial que se esconde detrás del velo corporativo y, con ello, continuar ejecutando contratos con el Estado, a pesar de las sanciones impuestas.

Ahora bien, como se mencionó, la asimetría punitiva lleva a que el funcionario público se integre a redes de criminalidad de mayor escala, que permite señalar que los demás procesos judiciales que se encuentran abiertos contra el exalcalde pueden multiplicar exponencialmente la utilidad del delito que hemos descrito brevemente. Empero, tanto en este proceso como en los otros asuntos judiciales, las estrategias judiciales parecerían allanar el terreno para el vencimiento de términos y conseguir una absolución formal, no por haberse descartado la responsabilidad, sino por el aprovechamiento de recursos y alternativas procesales que pueden ampliar el horizonte de tiempo hasta el punto de inhibir la acción judicial. Inclusive, en entrevista de 2015, el abogado del acusado afirmó que no se trataba de estrategias procesales, sino "Se piden garantías procesales consagradas en la Constitución y en los tratados internacionales, que son de carácter obligatorio" (Lancheros, 2015).

En efecto, en el otro extremo de esta red de criminalidad (los contratistas Manuel, Miguel y Guido Nule), se estima, solo en diez contratos 
con el distrito, extrajeron más de doce millones y medio de dólares. La pena que se les impuso fue de 19 años y una multa de $\$ 13055$ millones de pesos (equivalente a 4 millones de dólares). Un cálculo similar al anteriormente realizado daría cuenta de, aplicando descuentos de la pena como el trabajo, el estudio y la enseñanza, la reducción de este tiempo de prisión hasta 9.5 años o 114 meses. Lo señalado se aproxima bastante a los evidentes incentivos que plantea el sistema jurídico penal y de contratación.

A esta batería de alternativas debe añadirse el tipo de centro de reclusión. En efecto, estos centros son de alta, media y mínima seguridad (establecimientos abiertos). El hacinamiento carcelario en Colombia ha producido que, entre otras medidas, se implementen brazaletes o mecanismo de vigilancia electrónicos que asigna la Unidad de Servicios Penitenciarios Carcelarios para presos que van a detención domiciliaria, y en el caso objeto de estudio, condujo a que el exalcalde se encuentre en la Escuela de Carabineros de la policía, en condiciones claramente beneficiosas. Estos medios electrónicos suponen otro incentivo, en la medida en que se conceden al reo cuya pena mínima prevista en la ley sea de ocho años de prisión o menos. ${ }^{4}$ Vale la pena aclarar que, en detención o prisión domiciliaria, el condenado puede redimir la pena

4 El artículo 23 de la Ley 1709 de 2014 establece "1. Que la sentencia se imponga por conducta punible cuya pena mínima prevista en la ley sea de ocho (8) años de prisión o menos.

2. Que no se trate de uno de los delitos incluidos en el inciso 2 del artículo 68A de la Ley 599 de 2000 [se refiere a la reincidencia].

3. Que se demuestre el arraigo familiar y social del condenado.

En todo caso corresponde al juez de conocimiento, que imponga la medida, establecer con todos los elementos de prueba allegados a la actuación la existencia o inexistencia del arraigo.

4. Que se garantice mediante caución el cumplimiento de las siguientes obligaciones:

a) No cambiar de residencia sin autorización, previa del funcionario judicial;

b) Que dentro del término que fije el juez sean reparados los daños ocasionados con el delito. El pago de la indemnización debe asegurarse mediante garantía personal, real, bancaria o mediante acuerdo con la víctima, salvo que demuestre insolvencia;

c) Comparecer personalmente ante la autoridad judicial que vigile el cumplimiento de la pena cuando fuere requerido para ello;

d) Permitir la entrada a la residencia de los servidores públicos encargados de realizar la vigilancia del cumplimiento de la reclusión. Además deberá cumplir las condiciones de seguridad que le hayan sido impuestas en la sentencia, las contenidas en los reglamentos del Inpec para el cumplimiento de la prisión domiciliaria y las adicionales que impusiere el Juez de Ejecución de Penas y Medidas de Seguridad". 
por educación, trabajo o estudio, con las mismas condiciones descritas previamente en este texto (Ley 1709 de 2014).

Como se constata, todos los delitos relativos a la contratación pública tienen como pena mínima entre 4 y 6 años, motivo por el cual, las personas que cometen delitos, como los señalados en este texto, pueden beneficiarse de prisión domiciliaria. De igual forma, aunque esta se encuentra condicionada al pago de indemnización por los daños causados por el delito, la misma norma señala la excepción de la insolvencia del reo.

En consideración a lo anterior, tendríamos pues que los costos morales, de cumplimiento, la utilidad del delito y la probabilidad del castigo se encuentran bastante alejados de una sanción penal óptima. La utilidad proyectada supera claramente el costo de cumplimiento y, a la luz de los beneficios procesales y penitenciarios, así como la asimetría punitiva, refleja un conjunto de incentivos jurídicos a la defraudación de las normas de la contratación pública y a la constitución de redes de criminalidad.

\section{Conclusiones}

En este documento se han presentado los insumos que el AED plantea sobre mercados implícitos como el derecho penal. Con ese marco operacional, abordamos un caso de estudio donde los costos morales, la probabilidad de castigo, los costos de cumplimiento y la utilidad esperada se conjugan en un escenario como el de la contratación pública, ofreciendo en su conjunto un abanico de incentivos a la criminalidad.

Los postulados antes mencionados parecerían sostener una hipótesis demostrativa que podría describir y ayudar a construir un sistema que contenga una sanción penal óptima, entendida como aquella que logra la prevención ideal y reduce el punto de equilibrio del delito. Por supuesto, se trata de un caso de estudio que parte de una premisa que no es predicable de todo el sistema penal, pues las redes de criminalidad que parecerían haberse tejido sobre la contratación pública están compuesta de delincuentes con acceso amplio o pleno a la información y a los medios para determinar la aplicación o no de las normas de 
contratación y las normas penales. Sin embargo, estos mismos insumos podrían extrapolarse a casos como las sanciones administrativas derivadas de la colusión en mercados, prácticas comerciales restrictivas y violación a los derechos del consumidor, así como delitos financieros, etc., donde las utilidades proyectadas superan notablemente los costos de cumplimiento y la simetría de información permitiría la construcción de redes de criminalidad que determinarían la ineficacia de la norma que intenta censurar conductas que producen costos sociales muy altos.

\section{Referencias}

Becker, G. S. (1968). Crime and punishment: An economic approach. En N. G. Fielding, A. Clarke, \& R. Witt (Eds.), The economic dimensions of crime (pp. 13-68). Palgrave Macmillan.

Colombia, Congreso de La República. Ley 65 de 1993 por la cual se expide el Código Penitenciario y Carcelario(19 agosto 1993).

Colombia, Congreso de La República. Ley 599 de 2000 por la cual se expide el Código Penal (24 julio 2000).

Colombia, Congreso de La República. Ley 906 de 2004 Por la cual se expide el Código de Procedimiento Penal. (Corregida de conformidad con el Decreto 2770 de 2004) (31 agosto 2004).

Colombia, Congreso de La República. Ley 1474 de 2011 Por la cual se dictan normas orientadas a fortalecer los mecanismos de prevención, investigación y sanción de actos de corrupción y la efectividad del control de la gestión pública (12 julio 2011).

Colombia, Congreso de La República. Ley 1709 de 2014 por medio de la cual se reforman algunos artículos de la Ley 65 de 1993, de la Ley 599 de 2000, de la Ley 55 de 1985 y se dictan otras disposiciones (20 enero 2014).

Cooter R., \& Ulen T. (1998). Derecho y economía. Fondo de cultura económica.

Fearon, G., \& Busch L. (2006) Auditing and competitive bidding in the public sector. Journal of Public Economics, 90, 657-678.

Fearon, G. (2009). Economics of public good provision: Auditing, outsourcing, and bribery. Canadian Journal of Economics, 42(3), 997-1022. http://dx.doi. org/10.1111/j.1540-5982.2009.01536.x 
García, M. G., C., Niño, N., Henao, A., Mejía, J. F., Rubiano, S., \& Castillo, C. (2009). Normas de papel: la cultura del incumplimiento de reglas. Siglo del Hombre Editores.

González, J. (1994). El análisis económico del derecho: algunas cuestiones sobre su justificación. Doxa.

González Tissinetti, A. (2007).Conceptos y aplicación de la delación compensada en la persecución de los carteles. http://repositorio.uchile.cl/handle/2250/152159

Kazakova, D. (2014): The new institutional economics within the present economic paradigm: A brief review. Ponencia presentada en The $8^{\text {th }}$ International Days of Statistics and Economics, Prague. http://msed.vse.cz/ static/msed_2014/article/381-Kazakova-Daria-paper.pdf

Kleiman, M. (2015). Cuando la fuerza bruta fracasa. Cómo lograr que haya menos crimen y menos castigo. Editorial Uniandes.

Lancheros, Y. (2015). 'Samuel Moreno no va a pedir su libertad'. El Tiempo. https://www.eltiempo.com/archivo/documento/CMS-16406179

Posner, R. (1998a). El análisis económico del derecho. Fondo de Cultura Económica.

Posner, R., Landes, W., E Kelman, M. (2011). Análisis económico del derecho. Siglo del Hombre Editores.

Posner, R, (1998b). The Problematics of Moral and Legal Theory. Harvard Law Review, 111, 1638-1709.

Restrepo, D. (2015) ¿Puede ser la mediación una vía de escape? El peligro del "parasitismo" y la necesidad de enfrentarlo. En D. P. Arias Holguín ¿Reformar o abolir el sistema penal? (pp. 225-256). Siglo del Hombre Editores.

San Miguel-Giralt, J. (2017). Contratación pública y colusión. Derecho de competencia frente al derecho administrativo. Vniversitas, 66(135), 377420. https://doi.org/10.11144/Javeriana.vj135.cpcd

Schäfer, H., E Ott, C. (1991). Manual de análisis económico del derecho civil. Editorial Tecnos S. A.

Uribe P., C. A. (2018). Retos del sistema de delación compensada y de la responsabilidad de las matrices por conductas de sus filiales. Una reflexión crítica desde y para el derecho comunitario andino. Vniversitas, 67(137). 